\title{
La aportación de Galicia a la Guerra de Secesión de Portugal (1640-1668)
}

\author{
Josefina Castilla SOTO* \\ Ana M. ${ }^{\text {a }}$ Cuba Regueira
}

Portugal habia conservado, desde su anexión en 1580, bajo el reinado de Felipe II, sus propias instituciones, lo que le había permitido desarrollarse como una nación casi independiente. Contaba además con un importante imperio ultramarino del que obtenía grandes ventajas económicas. Olivares era plenamente consciente del valor que Portugal representaba en el ámbito de la Monarquía Hispánica. "Los reinos, Señor, de Portugal son, sin duda, de lo mejor que hay en España, asi por la fertilidad de la tierra en algunas partes como por la disposición de las otras para la mercancía con los puertos excelentes que hay en aquellos reinos; son abundantes de gente y por la disposición dicha, de personas de gran caudal..." '.

Concretamente la fachada marítima portuguesa, constituia un enclave estratégico y marítimo de primer orden para la política internacional y ultramarina de Castilla.

Olivares, mediante su conocido proyecto de la "Unión de Armas", se habia propuesto una "castellanización" de la Península en toda su extensión, lo que se traducia en una mayor presión fiscal. Las continuas peticiones, tanto tributarias como militares del Conde-Duque, fueron respondidas con sucesivos levantamientos en Oporto (1628), Santarém (1629) y Évora (1637). Además las clases altas portuguesas, que en 1580 habian apoyado la candidatura de Felipe II al trono portugués esperando obtener importantes beneficios comerciales de la unión con el imperio colonial his-

UNED

Maranon, G. El Conde-Duque de Olivares (la pasión de mandar). Madrid, 1980, apéndice XVIII, pág. 441. Se trata de un fragmento de la Instrucción que dio en 1625 el Conde-Duque a Felipe IV, sobre el gobierno de España. 
pano, se encontraban ahora desengañadas al contemplar cómo los enemigos de España atacaban sus posesiones coloniales.

La conjura nobiliaria se hizo patente en Portugal, alrededor del duque de Braganza. En repetidas ocasiones intentó el Conde-Duque sacar al de Braganza de Portugal mediante el ofrecimiento del Virreinato de Milán o del desempeño de algún cargo importante en la Corte, pero con resultados adversos.

Aprovechando la circunstancia de que las fuerzas militares castellanas se estaban empleando en el frente catalán, los portugueses se levantaron en armas y proclamaron al duque de Braganza Rey de Portugal, con el nombre de Juan IV. Era el 1 de diciembre de 1640.

En Portugal nos encontramos con un movimiento político de la nación, pero no un movimiento popular, excepto en la medida en que las masas demostraron respaldar firmemente la actuación de su clase gobernante ${ }^{2}$.

Desde un principio y ante la multitud de frentes abiertos en la política exterior de Felipe IV, Portugal resultó el más sacrificado por considerar las altas esferas políticas que era menos peligroso su levantamiento, que la intromisión francesa en Cataluña, cuyo avance podía poner en serio aprieto a Aragón e incluso a Madrid. Por ello, la campaña portuguesa durante varios años se limitó a escaramuzas fronterizas de escasas consecuencias, una especie de "guerra menor" por ambas partes; los robos, correrías y desolaciones eran continuas. "El portugués ha entrado ahora nuevamente por la Puebla de Sanabria, tres leguas de Benavente $y$ ha quemado tres lugares y alguna gente que no se pudo escapar, como niños, mujeres, y se han llevado todo cuanto tenían, bueno y malo" ${ }^{3}$.

Los enemigos de España se apresuraron a prestar su ayuda al levantamiento portugués. Francia empezó a enviarle socorros en 1641 mientras que en 1642 se concertaba una alianza entre Inglaterra y Portugal. Luis XIV no dejaría de enviar auxilios a los portugueses, ni siquiera tras la firma de la Paz de los Pirineos. Por su parte, el monarca inglés Carlos II, que había vivido largos años en el exilio al amparo de la hospitalidad española ${ }^{4}$, acabó

E..LIOT7, J.H., y otros, Revoluciones y rebeliones de la Europa moderna. Madrid, 1972, pág. 140. BarkRIOnuevo, J., Avisos. Madrid, 1968, vol. I. pág. 77: 1 de noviembre de 1654.

CASTIL la Soto, J., "Las relaciones entre Felipe IV y Carlos II de Inglaterra, durante el protectorado de Cromwell (1656-1659)", Espacio. Tiempo y Forma, serie IV, t. 2, 1989, pags. 111124 
concertando su matrimonio con una infanta portuguesa que aportaba una importante dote.

$\mathrm{Ni}$ a Francia ni a Inglaterra les interesaba que la península volviera a formar un solo bloque, y frente a esta razón, de nada servían amistades ni parentescos regios.

El principal escenario de esta larga guerra fue casi siempre Extremadura. Galicia, en cambio, será un campo de operaciones secundario, salvo en la última etapa (1665-1667). Además, ambos bandos utilizaron la lucha en la frontera gallega, como maniobra de distracción para impedir la concentración de tropas en tierras extremeño-portuguesas. De todas formas, en ambas zonas se producirian grandes períodos de inactividad, aunque siempre más numerosos en la frontera gallega.

Pero será del desarrollo de esta guerra en la frontera de Galicia, de lo que a continuación nos ocuparemos. Siguiendo a E. González López ${ }^{5}$, podemos considerar que se desarrolló en cuatro fases:

1. 'a fase: $1640-1656$

2. a fase: $1657-1665$

3. fase: $1665-1667$

4. ${ }^{a}$ fase: $1667-1668$

Durante la primera larga etapa destacaron, sobre todo, la impopularidad de la guerra en Galicia, sólo apoyada por la pequeña nobleza gallega que pretendia alcanzar la gloria militar, y la resistencia a las levas militares por parte de todas las clases sociales, en particular de los estudiantes compostelanos.

Durante los primeros meses el frente gallego permaneció inactivo, dándose fundamentalmente el reclutamiento de tropas. Las milicias no serian solamente de los lugares fronterizos sino de todo el reino. Por otra parte, España seguía manteniendo viva la ficción de Portugal como parte integrante de la monanrquia española, nombrando incluso a dos nobles gallegos como gobernadores de las provincias portuguesas limítrofes con Galicia.

La misma Junta del Reino de Galicia ${ }^{6}$, por el carácter defensivo de la guerra en sus fronteras, solicitó la reducción a 3.000 hombres, de los

Gonzalez. Lopez, E., Historia de Galicia. La Coruña, 1980, págs. 357-364.

Era un órgano intermedio entre el Reino y la Corona. Su función consistía en gestionar y poner en marcha las peticiones que la Corona hacia, al tiempo que presentaban al Rey las necesidades de los naturales de Galicia. Carecia de funciones gubernativas, aunque en estos momentos era más tenida en cuenta, ya que a partir de la consecución del voto en Cortes (1623). Galicia habia cobrado mayor personalidad administrativa. 
16.000 con los que había prometido contribuir para las plazas de Tuy y Monterrey (cuarteles de las dos zonas en que se habia dividido la frontera gallega).

Como hechos más significativos en esta primera fase, hay que reseñar la destrucción del monasterio benedictino de Fiaes (en la zona entre Duero y Miño) en 1641, la victoria de las tropas gallegas en Villaza en 1642 y la pérdida de la fortaleza de Salvatierra de Miño ese mismo año y que no se recuperaria hasta 1659.

Durante algunos años se estableció una especie de tregua tácita a ambos lados de la frontera. En años sucesivos, salvo los intentos de recuperar Salvatierra y algunas razzias efectuadas por parte de ambos ejércitos, no se registró ningún hecho digno de mención.

La segunda fase coincidió con el reinado de Alfonso VI y con los últimos años de Felipe IV. Durante esta fase se registró una mayor actividad bélica en la frontera gallega, aunque esta zona se mantuvo como un teatro secundario de la guerra.

En la primera parte de esta fase (años 1658-1659) se produjeron notables victorias de las fuerzas gallegas. Asi en 1658 los gallegos tomaron la fortaleza de Lapela, recuperando en 1659 la emblemática Salvatierra. Este embate en la frontera gallega y la concentración de un poderoso ejército español en Extremadura, hicieron que Portugal buscara ayudas en Europa: dinero y oficiales que reestructuraran el ejército portugués. Por fin, la monarquia encontraba tiempo y medios para dedicarlos a poner orden en el frente portugués: "se considera por precisa y necesaria la recuperación del Reino de Portugal, teniéndose por la empresa de más crédito y consecuencia en que mis Reales armas deben emplearse" ?.

Se prepararon tres ejércitos:

1. Ejército de Badajoz: atacaria desde Extremadura, estaría mandado por don Juan José de Austria y contaría con un contingente aproximado de 16.000 infantes y unos 6.000 caballos.

2. Ejército de Galicia: mandado por el marqués de Viana y con unos efectivos para la campaña de 1662 , que rondaban los $19.000^{8}$.

Archivo General de Simancas (AGS), Estado, leg. 3517, fol. 279 y AGS. Estado, leg. 6152

Biblioteca Nacional de Madrid (BNM), Ms., 2396, fol. 238. Los efectivos del Ejercito de Galicia, quedaban desglosados de la siguiente manera:

$\begin{array}{lr}\text { - soldados veteranos ....................................... } & 8.935 \\ \text { - soldados milicianos ...................................... } & 4.500 \\ \text { - soldados para el tren de artillería................... } & 500\end{array}$ 


\section{Ejército de Ciudad Rodrigo: capitaneado por el duque de Osuna.}

Sin embargo, en Galicia, la guerra se hacía cada vez más impopular y se produjeron levantamientos de hombres y mujeres (sobre todo en La Coruña en 1662), que se amotinaron contra las levas.

Los últimos años de esta fase significaron el resurgir del ejército portugués y el final de la victoriosa campaña de las tropas gallegas. Contingentes portugueses comenzaron a concentrarse en la frontera, amenazando sobre todo Monterrey, lo que provocó que por primera vez los estudiantes de Santiago formaran el llamado «Primer Batallón Literario Compostelano", que no llegó a entrar en acción, ya que la maniobra portuguesa no era más que una forma de alejar el centro de interés de la frontera extremeña, donde se preparaba una gran ofensiva. Además, coincidiendo con la subida al trono de Carlos II (1665), los portugueses, acaudillados por Schomberg, lanzaron un gran ataque que amenazó todo el sur de la provincia de Pontevedra (Tuy, Bayona, Vigo, Gondomar, etc...). La idea era apoderarse del puerto de Vigo, objetivo primordial de los franceses. La ocupación del valle del Rosal y la rendición de la pequeña guarnición de La Guardia pusieron punto final a esta fase.

Durante la tercera fase la frontera gallega pasó a ser el teatro principal de la guerra, al tiempo que se despertaba la conciencia colectiva de Galicia. Como consecuencia de la ofensiva portuguesa, en esta fase (1665-1667) tuvieron lugar dos hechos destacados. Por una parte, la convocatoria en asamblea de la pequeña nobleza gallega que presentó al gobierno español una serie de demandas, sugerencias y quejas, relacionadas con la marcha de la guerra ${ }^{9}$. Por otra, la formación del "Segundo Batalıón Literario Compostelano», que fue enviado al frente de Goián.

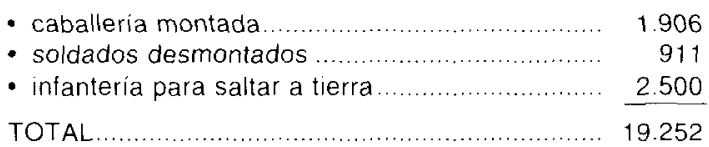

La asamblea fue convocada en Pexegueiro de Abaixo (Orense) por el caballero gallego Lope de Taboada y Ulloa. Se llegó a los siguientes puntos:

- Sugerencias y quejas a las autoridades civiles y militares sobre la marcha de la guerra y el papel en ella de la nobleza gallega (casi todos sus miembros eran oficiales de milicias en la frontera).

- Petición del reconocimiento, por parte de las autoridades, de las prerrogativas que tradicionalmente correspondian a la nobleza

- Solicitud de que un representante de la nobleza gallega asistiera a las reuniones de los Consejos de Guerra que, en el frente gallego, trazaba los planes de campaña. Este mismo representante serviria de enlace entre el Capitán General de la región, los tercios, las milicias y los voluntarios gallegos del ejército. 
Los saqueos de las tierras que circundaban las dos posiciones tomadas por los portugueses (Goián y La Guardia), eran frenadas por las tropas gallegas, al mando del nuevo Capitán General de Galicia, Iñigo Fernández de Velasco, Condestable de Castilla. Se produjo entonces una especie de tregua tácita en la frontera gallega, ayudada por los intentos de pacificación de Castelho Mellor y el embajador inglés en Madrid, aunque las intrigas francesas paralizaron, de momento, el intento.

En la última fase (1667-1668), la paz ya reinaba prácticamente en la frontera gallega. Inglaterra logró al fin la suspensión de las hostilidades en todas las fronteras, temerosa de la influencia de Francia en Europa. Asi el 18 de febrero de 1668, se firmó el tratado de paz, reconociendo la independencia de Portugal y determinándose la restitución de todas las conquistas hechas durante la guerra, excepto Ceuta ${ }^{10}$.

Dejando ya a un lado las fases que constituyen el desarrollo de la guerra en la frontera entre Galicia y Portugal, parece oportuno centrarnos ya más concretamente en las aportaciones de Galicia a la guerra de secesión portuguesa (1640-1668).

Como ya se apuntó anteriormente, la frontera de Galicia con Portugal fue casi siempre, en el transcurso de este proceso bélico, un frente secundario; a pesar de esta circunstancia, la contribución que soportaron los gallegos resultó muy gravosa para sus efectivos humanos y para sus ya menguados y escasos recursos económicos.

Cuando se produjo el levantamiento de Portugal, el 1 de diciembre de 1640 , la Junta del Reino se hallaba reunida en La Coruña, y en la sesión del dia 17 acordó escribir al Rey para transmititle su pesar y ponerse a su disposición".

El levantamiento de Portugal sorprendió a Galicia casi desguarnecida e inerme, según se desprende de la carta dirigida al Rey por la Junta del

- Don Lope de Taboada, en nombre de la nobleza gallega, recorrería Galicia para comprobar la movilización general de todas las clases sociales (para que no se sustrajeran los hijos de los ricos burgueses o de los influyentes funcionarios)

- Como prerrogativa y al margen de la guerra se pedia que fuera un representante de la nobleza gallega, y no el Capitán General de Galicia, quien hiciera la ofrenda al Apóstol Santiago en su día.

- Y por fin, que en los dias de fiesta del Apóstol se reunieran en Santiago los nobles gallegos para discutir los asuntos del Reino y los de la nobleza.

Ver CASIII LA SOIO, J., "Algunas consideraciones sobre la lealtad de Ceuta a la Corona Hispánica en 1640". Espacio. Tiempo y Forma. 1991, págs. 125-135.

VV.AA., Actas de las Juntas del Reino de Galicia. vol. IV (1640-1641), pág. 223. La carta está fechada el 17 de diciembre de 1640 . 
Reino, datada en Bayona el 18 de enero de 1641 en la que, entre otras cosas, le comunicaba lo siguiente:

“...para la reducción de aquel Reino (Portugal), reconocida la obstinación de sus naturales, siendo Vuestra Magestad servido, se habrán de hacer los acometimientos por entrada y diversión con las milicias y naturales de este (Galicia); y como no hay en él infanteria vieja por haberse sacado para Flandes y Cataluna, menos de que se provea de numero conveniente para su abrigo, obrarán poco por sí solas, respecto de faltarles la plática y disciplina necesaria para tales empresas y cabezas que la gobiernen; y las companías de a caballo que aquí habia de Vergantinos con lanzas y ahora se han mudado de caravinas, necesitan de guarnición de corazas y, faltándole. van arraigadas a cualquier fracaso; y asimismo como el tren de la artillería es una de las principales partes del ejercicio, sirvase Vuestra Magestad de mandar se remita uno de los que fueron a Vizcaya con capitán y ministros pláticos de su manejo, municiones e ingeniero al arte, porque de las que el año pasado se condujeron a este Reino, se ha distribuido parte en la armada y gastándose en la presente ocasión las demás, queda sin ellas este Reino y sus plazas y puertos abiertos con notorio peligro... ${ }^{1:}$.

A las sucesivas reorganizaciones de los ejércitos que operaban en la frontera galaico-portuguesa ${ }^{13}$, a su intendencia, y al levantamiento y reparación de sus fortificaciones contribuyó Galicia durante esta guerra, oponiéndose reiteradamente sus naturales y resistiendo la Junta del Reino.

La primera de estas contribuciones se produjo en los meses iniciales de 1641 a base de dos ejércitos, el de Tuy y el de Monterrey ${ }^{14}$. La leva y sostenimiento de estos dos ejércitos, que se mantuvieron operativos en la frontera hasta 1644, no estuvo exenta de problemas. Efectivamente, esta leva para la guerra con Portugal vino a sumarse a otras que se habian realizado ya con anterioridad para atender a otros frentes (Flandes, Cantabria, Cataluña, etc...), que los procuradores de la Junta de 1643 cuantificación en unos 34.000 . El resultado de las mismas, según los representantes de las ciudades y provincias, fue que «queda el Reino casi despoblado y no hay gente que acuda a la labranza y cultura de los campos con lo cual se pierde el Reino y quedan las tierras baldias... » Por ello pidieron "se suplique a su Magestad se sirva de probar de gente vieja

lbidem. págs. 239-240

En esta época, esta frontera tenía dos sectores: uno fluvial, cuya divisoria la constituia el rio Miño, y el otro terrestre que discurría por el sur de la actual provincia de Orense. Sus centros respectivos eran Tuy y Monterrey.

El ejército de Tuy estaba integrado por 10.000 hombres gallegos de a pie y unos 1.000 a caballo. El de Monterrey lo formaban unos 4.000 infantes. 
para este ejército, para que con eso sea menor el número de soldados que asistan en él y se pueda acudir a la labranza y cultura... ${ }^{15}$.

Otro motivo de queja por parte de los procuradores fue el sacar municiones, pertrechos, ... de las plazas de La Coruña y Bayona para llevarlos a la raya de Portugal, dejando desguarnecidas a éstas, cuando Francia y Holanda preparaban sus armadas para socorrer a Portugal ${ }^{16}$.

Una vez comprobado que el levantamiento de Portugal no era un mero acontecimiento efímero, la Junta del Reino aprobó la aportación de 16.000 soldados para la defensa de Galicia. Esta cifra se mantuvo, al menos, hasta abril de 1664, fecha en la que el entonces Gobernador y Capitán General de Galicia, Luis de Poderico, propuso a la Junta del Reino ${ }^{17}$ un conjunto de cambios en relación con estas milicias: reducción a 10.000 soldados agrupados en 10 tercios de 10 compañías cada uno, mandados por caballeros del Reino (maestres de campo, sargentos, mayores, capitanes, etc....). Esta transformación de las anteriores milicias ocasionales en fuerzas equiparables a la infantería buscaba dos efectos:

1. Su capacitación para la campaña, al estar mejor preparados.

2. Permitir a los demás naturales, por la disminución del número de reclutados, dedicarse a las tareas agrarias.

El Reino de Galicia no sólo tuvo que contribuir con hombres a la guerra con Portugal, sino que además se vio obligado a ocuparse de la intendencia de las tropas que operaban en su frontera con los lusitanos. Es cierto que durante un corto número de años, tal vez 1646 y 1647, la Hacienda Real destinaba 360.000 escudos a este fin, provenientes en su mayor parte de lo recaudado en Galicia. En los años posteriores, para evitar los inconvenientes, Galicia se hizo cargo directamente del armamento, de las fortificaciones, de los forrajes, del alojamiento de la caballería, del transporte de la artilleria, del abastecimiento de leña, del alquiler de las casas para los mandos del ejército y de la provisión de camas para los soldados.

En cuanto a las armas, los soldados de milicias, también llamados de pilas (parroquias) o pilones, debian acudir con ellas a las campañas; pero el Reino de Galicia quedó inerme e indefenso como consecuencia de las continuas guerras que acontecian por aquellos años.

Archivo Historico Provincial de Lugo (AHPL). Ayuntamiento Juntas del Reino (AJR), lib. 1. Junta de 1643 celebrada en enero y febrero en La Coruña

AHPL, AJR, lib. 1, reunion en Tuy, el 7 de marzo de 1641

AHPL, AJR, lib. 1, reunión en Tuy, el 1 de abrit de 1664. 
Aunque a comienzos del conflicto con Portugal, el aprovisionamiento de forrajes para la caballería corría a cargo de la Hacienda Real, pronto el Reino se vio forzado a suministrarlos. Así, los procuradores en la Junta del Reino en 1646, se quejaron del uso fraudulento que hacian de la cebada los capitanes del ejército ${ }^{18}$.

Pero además, era necesario alojar a la caballeria en las casas, al finalizar las campañas, por no tener cabida en las plazas. Otras prestaciones de los gallegos a la guerra eran igualmente la leña, el pago por parte de la ciudad de Tuy de los alquileres de las casas que alli habitaban los jefes y cabos militares, el coste de las camas para los soldados de las fronteras y el transporte en carros del material militar ${ }^{19}$.

Finalmente, hay que aludir a la participación de los estudiantes compostelanos en la guerra. Tras su negativa a formar parte en ella durante los primeros años de la misma, en los años 1663 y 1665 se formaron sendos batallones literarios. La organización del primer Batallón Literario se llevó a cabo a raíz del ataque de las tropas portuguesas a Monterrey ${ }^{20}$ y tuvo una efectividad bélica más bien escasa.

La invasión de una parte del territorio gallego sureño por parte de las fuerzas internacionales mandadas por Schomberg motivó la constitución del Segundo Batallón Literario.

Si tuviéramos que centrarnos en las reacciones surgidas en Galicia contra la guerra, deberíamos concluir que esta guerra fraticida con Portugal fue casi siempre poco aceptada por los gallegos.

La Junta del Reino, en los meses iniciales de la guerra, se puso, según se analizó ya, a disposición del marqués de Valparaíso, por aquel entonces Gobernador y Capitán General de Galicia, acompañándolo hacia la frontera, pero en los años restantes su actitud fue de constante obstrucción, oponiéndose a los subsidios extraordinarios para la misma y solicitando la disminución de su cuantía y la rebaja del cupo de soldados a reclutar. Estas voces se dejaron oír en determinadas ocasiones y así por

AHPL. AJR, lib. 1, reunión en Pontevedra, el 9 de junio de 1646

La provincia de Tuy contribuia especialmente con carros y ganado "transportando piezas y más tren de artillería. municiones. barcas. puentes, maderas, viveres, bagajes y todo lo demás necesario para el sustento y conservación del ejercito. asi a Portugal como a las demás partes y pla. zas de la frontera". En AHPL. AJR, lib. 1, reunión celebrada en Pontevedra, el 6 de julio de 1660

Gowi Al.t. Lopi z. E.. El Aguila caida. Vigo, 1973, pag. 198. Dice que el mencionado ataque portugues a la plaza de Monterrey tuvo la virtualidad de hacer atractiva, para diversos sectores sociales. una guerra que hasta entonces no lo habia sido. En el caso de los estudiantes composteanos. muchos de ellos habian sido aluminos del colegio de los jesuitas de Monterrey 
Cédula de 19 de marzo de 1659, a instancias del marqués de Viana, entonces Gobernador y Capitán General de Galicia, Felipe IV relevó a la Villa de Monzón y a los demás lugares reducidos a su obediencia, en la provincia entre Duero y Miño, del pago de todos los tributos, por espacio de dos años. De este modo se les otorgaba a los pueblos la posibilidad de reparar los daños ocasionados por la guerra ${ }^{21}$.

El 6 de abril de 1661, el Rey por resolución de una consulta del Consejo de Portugal, concedió una prórroga de un año para la exención de impuestos, contemplada en la Cédula del 59. De este modo se atendía la súplica elevada por los moradores de Monzón, Valadares y otras localidades, quienes habian manifestado la imposibilidad, en los dos años transcurridos, de reparar sus casas y resarcirse de los desórdenes causados por la guerra. Sin embargo, haciendo caso omiso de esta prórroga, el marqués de Viana, al verse acosado por la necesidad, decidió imponer a los lugares reducidos una contribución, durante los meses de mayo, junio y julio (1661), de 520 haces de hierba diarios, para los 260 caballos existentes en la zona. Estas localidades enviaron rápida protesta al Consejo de Portugal, alegando que se les había prorrogado durante un año más la exención de impuestos, pero que, aún en el caso de no habérseles concedido dicha prórroga, la Cédula del 59 dejaba claro que tras su disfrute, volverian a pagar los tributos existentes antes de la rebelión y éste, sobre la hierba, no existía, era de nueva imposición.

Finalmente, el Consejo aunque solapadamente, se puso del lado de los agraviados ${ }^{22}$. Sin embargo, estas medidas, en principio sólo dirigidas a los lugares recuperados, no impidieron que la zona fronteriza fuera importantemente dañada por el desarrollo de las continuas campañas y las exigencias de tropas y dinero que éstas suponían.

En cuanto a las levas, los estudiantes compostelanos, pertenecientes en su inmensa mayoria a la hidalguía, se opusieron inicialmente a los intentos de su reclutamiento para la guerra, aunque acabaron alistándose en los batallones literarios. Por su parte, las masas populares se opusieron casi sistemáticamente a las levas de soldados de pilas, por el modo abusivo de efectuarlas los mandos del ejército y por sus repercusiones socia-

\section{AGS, SP, Leg. 2641}

"V. Magestad se sirva de mandar remitirle (se refiere al marqués de Viana) los autos del dicho agravio, para que por lo que en él se refiere y las razones que hay en favor de aquellos lugares y conveniencias del servicio de $\mathrm{V}$. Mg. para el ejemplar que conviene dar a los lugares que no se han reducido" (BNM, Mss. 2388, fol. 19. Consulta del Consejo de Portugal al Consejo de Estado de 25 de junio de 1661) 
les y económicas (abandono de las faenas agrarias, despoblación...). Quizás el motin contra las levas más conocido fue el que tuvo lugar en La Coruña el 30 de octubre de 1662.

En cuanto a los alojamientos, al finalizar la campaña de 1662 se publicó un Reglamento para evitar los daños y abusos que se originaban del tránsito por la provincia, tanto de la infantería como de la caballería ${ }^{23}$. A propósito del mismo, el Rey envió una Real Cédula fechada en Madrid, el 20 de septiembre de 1662, en la que aprobaba dicha iniciativa y ratificaba el Reglamento: "agradezco el cuidado y trabajo que habéis puesto en elio, encargándoos que cuidéis mucho de que se observe y de que se eviten excesos de los soldados, haciendo castigar severa y ejemplarmente a los que los cometieren... he resuelto que a los lugares que tuvieren alojamiento, se les reciba en cuenta el gasto de ellos, de lo que debieren pagar a mis Rentas Reales..." ${ }^{24}$.

A pesar de esta reglamentación para encauzar los alojamientos de los soldados, los cuarteles de invierno no se utilizaban convenientemente para disciplinar y endurecer en el arte de la guerra a los bisoños. Además resultaba muy difícil frenar la tendencia de los soldados a cometer abusos en su entorno; así el Corregidor de Monzón, dirigiéndose al Consejo de Portugal, puso en su conocimiento el mal estado de las feligresías obedientes, debido a los excesos de los soldados, durante su alojamiento.

Otra forma de resistencia frente a la guerra fue el fraude en la prestación del servicio de carruajes y yugadas necesario para mover el ejército, especialmente la artillería. Para llevarlo a cabo enviaban los carros en mal estado y los bueyes achacosos e incluso, a veces no los alimentaban por el camino con el objeto de que murieran y de ese modo, dar por finalizada la prestación de esta obligación ${ }^{25}$. En este sentido conviene destacar la labor llevada a cabo por la Junta del Reino de Galicia ${ }^{26}$. La postura de esta Junta fue enérgica y valiente en algunas ocasiones, para oponerse a ciertas levas militares excesivas. Esta resistencia frenó algunas movilizaciones, moderó los cupos o contingentes durante la guerra con Portugal y

BNM, Mss. 2389, fols. 17 y 18

Ibidem, fol. 13.

AHPL. AJR, lib. 1.

La Junta del Reino no era una institución equivalente a unas Cortes particulares del reino de Galicia, con independencia legislativa y fiscal. No eran ni siquiera un órgano ejecutivo, pero asumieron como dos objetivos prioritarios de su razón de ser. la defensa de los naturales en materia de cargas fiscales y en materia de levas militares. 
consiguió alguna mejora en las condiciones de vida de los soldados gallegos movilizados en los presidios y fronteras.

Lo cierto es que poco a poco y contra todo pronóstico, Portugal iba logrando victorias importantes en el camino hacia su independencia, gracias a la poderosa colaboración de Francia e Inglaterra en el campo de batalla y de Francia, Inglaterra y Holanda, en calidad de proveedores de viveres, municiones, armas, etc..., por vía marítima. De nada sirvieron las medidas adoptadas para impedir la llegada de auxilios a los rebeldes ${ }^{27}$.

Fueron inútiles los sacrificios cedidos a lo largo de la frontera con Portugal, especialmente los realizados por extremeños y gallegos. Portugal lograba su independencia ante los ojos expectantes de la Monarquía Hispánica:

«Dicen a Vuestra Magestad que Portugal no tiene dinero, no tiene navíos, no tiene gente: traidores son los que lo dicen. Pues ¿con qué nos tienen destruidos? Sin gente nos tienen tantas veces desbaratados; ¡Válgame Dios, qué fuera con gente! Sin dinero lloramos nuestras ruinas, ¿qué lloráramos si tuvieran dinero? Señor: Portugal nos desbarató en Montijo, nos destruyó en Yelbes, Luis Méndez de Haro huyó dejando caballos, artillería, infantes y bagajes. Portugal en Évora destruyó la flor de España, lo mejor de Flandes. lo lucido de Milán, lo escogido de Nápoles y lo granado de Extremadura. Vergonzosamente se retiró S.A. dejando ocho millones que costó la empresa, ocho mil muertos, seis mil prisioneros, cuatro mil caballos, veinticuatro piezas de artilleria, y lo más lastimoso fue que, de ciento veinte títulos y cabos, no escaparon sino cinco (...). Cada día espera Vuestra Magestad que se gane, y cada día sepa Vuestra Magestad que se pierde, y que es mucha la pérdida de cada día» ${ }^{28}$.

Antes de iniciarse la campaña de 1663, Felipe IV contrató con Juan Jorge de Muller, una serie de navios de guerra para servir en corso contra los rebeldes de Portugal. Los objetivos fundamentales consistian en atacar o apresar a cuantos navios portugueses encontraran en su camino, asi como a las naves de otras naciones que estuvieran prestándoles su apoyo o proporcionándoles viveres y bastimentos.

Semanario Erudito, vol. V. Madrid, 1787, pág. 93. BNM, Mss. 11033, fols. 80 y ss. Se trata del comentario de un Ministro de Felipe IV refiriéndose a la desastrosa campaña del 63. 